\title{
Increased Levels of Chitotriosidase and YKL-40 in Cerebrospinal Fluid from Patients with Alzheimer's Disease
}

\author{
Christoffer Rosén $^{a} \quad$ Carl-Henrik Andersson ${ }^{a} \quad$ Ulf Andreasson ${ }^{a}$ \\ José L. Molinuevo ${ }^{b} \quad$ Maria Bjerke ${ }^{a}$ Lorena Rami $^{b} \quad$ Albert Lladób $^{b}$ \\ Kaj Blennow ${ }^{a}$ Henrik Zetterberg ${ }^{a}$ c \\ ${ }^{a}$ Clinical Neurochemistry Laboratory, Institute of Neuroscience and Physiology, Department \\ of Psychiatry and Neurochemistry, the Sahlgrenska Academy, University of Gothenburg, \\ Mölndal, Sweden; ${ }^{b}$ Alzheimer's Disease and Other Cognitive Disorders Unit, Hospital Clinic, \\ IDIBAPS, Barcelona, Spain; ' $\mathrm{C} C L$ Institute of Neurology, London, UK
}

Key Words

Alzheimer's disease $\cdot$ Cerebrospinal fluid $\cdot$ Biomarkers $\cdot$ Inflammation

\section{Abstract}

Background: The cerebrospinal fluid (CSF) biomarkers total tau, abnormally phosphorylated tau and amyloid $\beta$ 1-42 are strongly associated with Alzheimer's disease (AD). Apart from the pathologic hallmarks that these biomarkers represent, other processes such as inflammation and microglial activation are present in the brains of patients with AD. New biomarkers related to these processes could be valuable for the diagnosis and follow-up of AD patients and for the evaluation of inflammation-related pathologies. Aim: The aim of this study was to evaluate the association of inflammatory CSF biomarkers with AD. Methods: Twenty-five AD patients and 25 controls who had a pathological and normal CSF profile of the core AD biomarkers, respectively, were included in this study. CSF levels of chitotriosidase, YKL-40 (also known as chitinase-3-like protein 1 ) and monocyte chemoattractant protein-1 (MCP-1) were quantified and the levels compared between the groups. Results: AD patients had increased CSF levels of chitotriosidase and YKL-40 (both approximately twice higher than in controls), while the levels of MCP-1 were similar in the AD and control groups. Conclusion: The results indicate that chitotriosidase and YKL-40 may be helpful for the evaluation of cerebral inflammatory activity in AD patients.

(C) 2014 S. Karger AG, Basel 


\section{Introduction}

Alzheimer's disease (AD) is a progressive neurodegenerative disorder that is characterized by neuronal loss, extracellular deposits of amyloid $\beta(A \beta)$ and intracellular accumulations of abnormally phosphorylated tau (P-tau) protein [1]. These features increase during the course of the disease and can be visualized upon autopsy of the brain [2]. However, indirect evidence of these changes can be acquired while the patient is still alive through brain imaging and cerebrospinal fluid (CSF) biomarkers. The CSF levels of total tau (T-tau) and abnormal P-tau protein are increased in AD patients, while levels of CSF A $\beta 42$ are decreased [3]. A large number of studies have shown that a profile with pathological levels of these three biomarkers is highly associated with $\mathrm{AD}$ and development of $\mathrm{AD}$ in patients with mild cognitive impairment (MCI) [4]. At present, there are insufficient data to evaluate their accuracy in predicting incipient AD in cognitively healthy individuals [5]. The biomarker profile can be used in research to increase the probability that a dementing process is caused by $\mathrm{AD}$, thus adding strength to further disease-specific analyses [6].

Apart from the above-mentioned pathological hallmarks, cerebral processes related to inflammation are highly present in AD patients. These processes may contribute to neuronal dysfunction and cell death in AD [7]. Epidemiological studies have shown delayed onset of AD in subjects using non-steroidal anti-inflammatory drugs $[8,9]$. Data from ultrastructural studies have shown an association between brain amyloid deposits and microglia as well as astrocytes $[10,11]$. Microglia are the main phagocytic immune cells in the CNS, but their role in relation to $\mathrm{AD}$ is not clear. Some evidence points towards an important role in the clearance of $A \beta[12]$, while other evidence suggests that microglia may contribute to the build-up of amyloid plaques $[13,14]$. Other theories state that microglial activation might mediate the neurodegeneration seen in the brain of AD patients [15]. Astrocytes have a trophic function for neurons. They can also modulate the activity of microglia and influence their reactivity to $A \beta[16]$.

Biomarkers reflecting inflammatory processes may provide new ways of evaluating patients with $\mathrm{AD}$. The recent finding of a missense mutation in TREM2 that may render microglia overactive to brain amyloid pathology and increases the AD risk about 4-fold [17, 18], has raised the interest in the role of microglia in the AD process. In this study, we wanted to investigate the association between $\mathrm{AD}$ and three candidate inflammatory CSF biomarkers.

The enzyme chitotriosidase is secreted by activated macrophages, and patients with Gaucher's disease (a disease characterized by malfunctioning lysosomal storage) have increased levels in plasma [19]. CSF levels of the enzyme have been assessed in AD patients and nondemented controls, with increased levels found in the former group, although with an overlap between the groups [20,21]. Another inflammatory biomarker is YKL-40 (also known as chitinase-3-like protein 1), a glycoprotein that structurally resembles chitotriosidase [22], and is mainly expressed in astrocytes in the brain [23, 24]. Some [24, 25], but not all [20], studies have found increased levels of YKL-40 in AD patients. The monocyte chemoattractant protein-1 [MCP-1, also known as chemokine CC motif ligand 2 (CCL2)] can be produced by microglia and is involved in the recruitment of monocytes in the central nervous system. Studies measuring the levels of MCP-1 have given contradictory results with either increased levels in patients with $\mathrm{AD}[26,27]$ and MCI [26] or no differences between AD patients and controls [20]. Some of the inconsistent data may be explained by heterogeneous $\mathrm{AD}$ and control groups.

The aim of this study was to quantify these three inflammatory biomarkers in AD patients with a pathological profile of T-tau, P-tau and $\mathrm{A} \beta 42$, and in cognitively healthy controls with a normal CSF profile to detect differences between the groups in which the biomarker-supported diagnostics minimises the risk of including preclinical $\mathrm{AD}$ patients in the control group and patients with AD-like memory impairment but without AD neuropathology in the AD group. 
Table 1. Clinical characteristics and comparisons of biomarker values between AD patients and controls

\begin{tabular}{|c|c|c|c|}
\hline & $\mathrm{AD}$ & Controls & $\begin{array}{l}\mathrm{p} \\
\text { values }\end{array}$ \\
\hline Age & $67.15(59.90-74.31)$ & $60.56(56.74-63.90)$ & \\
\hline Gender, n (male/female) & $9 / 16$ & $9 / 16$ & \\
\hline \multicolumn{4}{|l|}{ ApoE, \% } \\
\hline$\varepsilon 2 / 3$ & 4 & 4 & \\
\hline$\varepsilon 3 / 3$ & 36 & 96 & \\
\hline$\varepsilon 3 / 4$ & 48 & 0 & \\
\hline$\varepsilon 4 / 4$ & 12 & 0 & \\
\hline MMSE & $21.00(18.00-24.00)$ & $29.00(28.00-30.00)$ & \\
\hline Chitotriosidase, nkat/l & $2.89(1.39-3.84)$ & $1.24(0.73-1.68)$ & 0.0007 \\
\hline $\mathrm{MCP}-1, \mathrm{pg} / \mathrm{ml}$ & $613.00(537.00-722.00)$ & $569.00(474.00-645.00)$ & n.s. \\
\hline YKL-40, ng/ml & $199,211.00(165,877.00-25,572.00)$ & $112,631.00(83,709.00-138,258.00)$ & $<0.0001$ \\
\hline $\mathrm{A} \beta 42, \mathrm{pg} / \mathrm{ml}$ & $326.00(273.70-370.00)$ & $750.00(663.92-851.10)$ & $<0.0001$ \\
\hline $\mathrm{T}$-tau, pg/ml & $873.50(713.90-1,059.90)$ & $206.50(155.89-240.66)$ & $<0.0001$ \\
\hline P-tau, pg/ml & $121.70(100.68-144.85)$ & $46.40(40.50-59.00)$ & $<0.0001$ \\
\hline
\end{tabular}

Values are medians with interquartile ranges in parentheses, except where otherwise indicated. ApoE = Apolipoprotein E; n.s. = not significant.

\section{Methods}

\section{Study Participants}

The AD and the control group were selected based on the core CSF biomarker profile in accordance with the International Work Group criteria for the diagnosis of AD [28] to yield highly specific clinical diagnosis with regard to neuropathological characteristics. The AD patients and controls were prospectively recruited from the Alzheimer's Disease and Other Cognitive Disorders Unit, Hospital Clinic, Barcelona, Spain. All subjects underwent clinical and neuropsychological assessment and lumbar puncture. Subjects with a history of stroke or seizure, parkinsonism, epilepsy or other neurological disease were not included in the study. The study was approved by the Hospital Clinic's ethics committee, and all participants gave written informed consent to participate in the study. Controls were healthy elderly individuals who presented no evidence of cognitive impairment (below 1.5 standard deviation) in any of the neuropsychological tests administered, and had a Mini-Mental State Examination (MMSE) score between 24 and 30 and a Clinical Dementia Rating (CDR) scale score of 0 . The AD patients were diagnosed with dementia according to the DSM-IV criteria for dementia [1] and met the criteria of probable AD, as defined by the NINCDS-ADRDA criteria [30]. They had a median MMSE score of 21, which indicates mild-to-moderate dementia. Patients with $\mathrm{AD}$ had a positive CSF biomarker profile with low levels of $\mathrm{A} \beta 42$ and increased levels of T-tau and P-tau (A $\beta 42<450 \mathrm{pg} / \mathrm{ml}$, T-tau $>500 \mathrm{pg} / \mathrm{ml}$ and P-tau $>75 \mathrm{pg} / \mathrm{ml})$, while the controls displayed a negative profile. Demographics and clinical characteristics are given in table 1.

\section{Biomarker Measurements}

The chitotriosidase activity in CSF was measured using an enzymatic assay, as described previously $[19,20]$. MCP-1 levels in CSF were measured using the Meso Scale Discovery technique (MSD Human MCP-1; Meso Scale Discovery, Gaithersburg, Md., USA). Levels of YKL-40 were determined using a sandwich enzyme-linked immunosorbent assay (ELISA) (R\&D Systems, Minneapolis, Minn., USA), which has been well validated in CSF [20, 25, 31, 32]. CSF 
Rosén et al.: Increased Levels of Chitotriosidase and YKL-40 in Cerebrospinal Fluid from Patients with Alzheimer's Disease
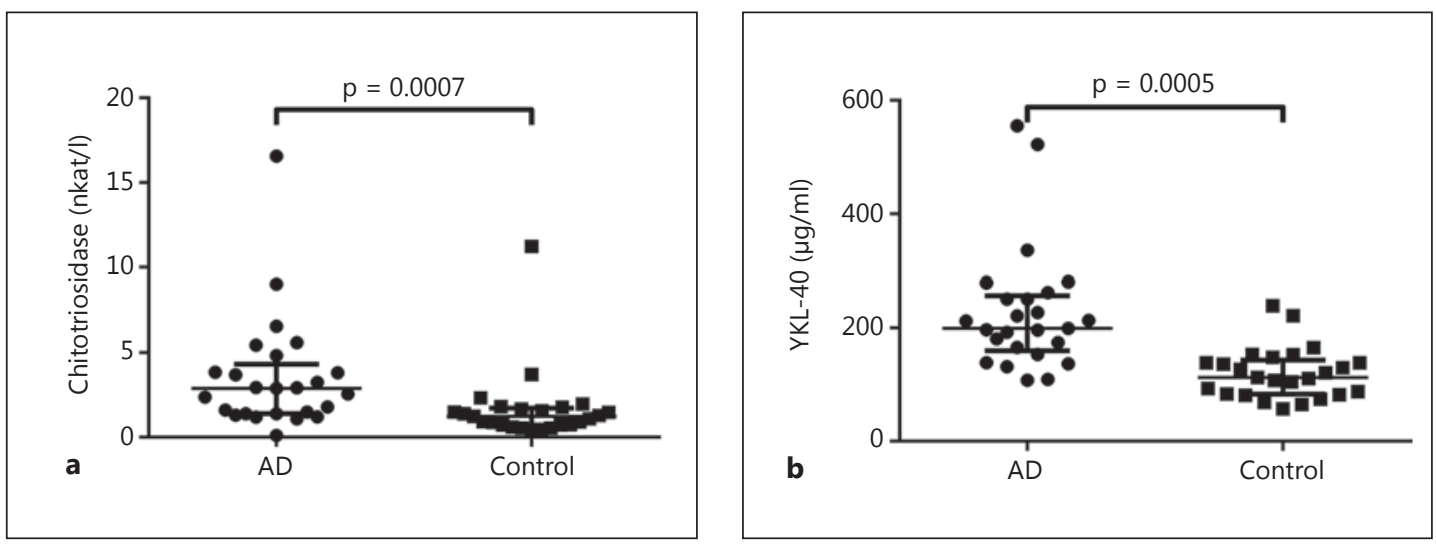

Fig. 1. Levels of chitotriosidase (a), YKL-40 (b) and MCP-1 (c) in AD patients and controls. Bars represent medians and interquartile ranges.

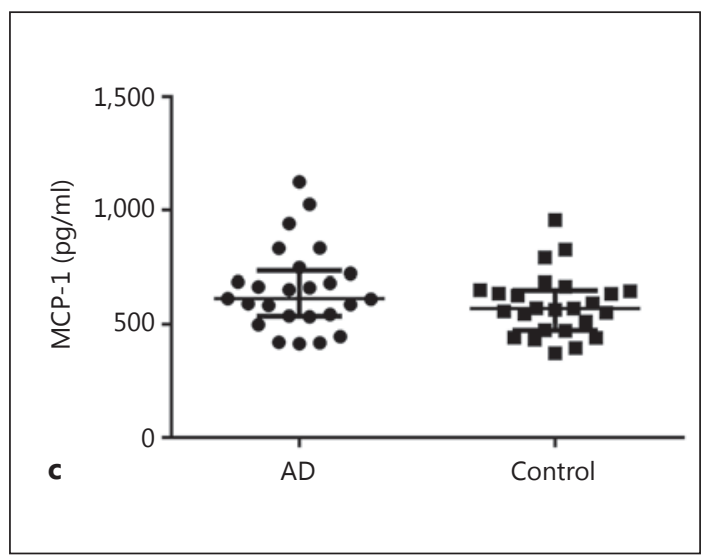

$\mathrm{A} \beta 1-42$ (called $\mathrm{A} \beta 42$ in this study) was quantified with a sandwich ELISA (Innotest $\beta$-amyloid ${ }_{1-42}$; Innogenetics, Ghent, Belgium) using a monoclonal antibody specific of the 42nd C-terminal amino acid on $\mathrm{A} \beta$ for capture and a biotinylated monoclonal antibody specific of the first five $\mathrm{N}$-terminal amino acids for detection, as described previously in detail [33]. CSF levels of T-tau were determined with a sandwich ELISA using monoclonal capture antibodies (Innotest hTAU-Ag; Innogenetics), as presented previously [34]. Levels of tau phosphorylated at threonine 181 (P-tau) were measured with a sandwich ELISA (Innotest Phospho-Tau[181P]; Innogenetics), as described previously in detail [35].

All measurements were performed in one round of analyses using one batch of reagents by board-certified laboratory technicians who were blind to the clinical characteristics of patients and controls. Intra-assay coefficients of variation were below $10 \%$.

\section{Statistical Analyses}

The software SAS version 9.3 (SAS Institute Inc., Cary, N.C., USA) was used for statistical analysis and graphs, together with GraphPad Prism 5 (GraphPad Software Inc., La Jolla, Calif., USA). Since data were skewed, group comparisons were made using the Mann-Whitney U test. Correlations were examined using Spearman rank correlation coefficient test. A $p$ value $<0.05$ was considered statistically significant. Receiver operating characteristic (ROC) curves for the differentiation of AD patients and controls were constructed, and the area under the ROC curve (AUROC) was calculated for the individual markers. 
Table 2. Correlations between biomarkers, gender and age

\begin{tabular}{|c|c|c|c|c|c|c|c|c|}
\hline \multirow[t]{2}{*}{$\mathrm{AD}$} & \multicolumn{8}{|c|}{ Controls } \\
\hline & T-tau & P-tau & $\mathrm{A} \beta 42$ & MCP-1 & chitotriosidase & YKL-40 & MMSE & age \\
\hline T-tau & & $0.75^{c}$ & $0.58^{\mathrm{b}}$ & 0.17 & 0.18 & 0.31 & 0.13 & $0.40^{\mathrm{a}}$ \\
\hline P-tau & $0.82^{c}$ & & $0.74^{\mathrm{c}}$ & 0.19 & 0.21 & 0.34 & 0.24 & 0.09 \\
\hline$A \beta 42$ & 0.35 & 0.26 & & 0.15 & 0.26 & 0.15 & 0.19 & 0.02 \\
\hline MCP-1 & 0.00 & 0.17 & 0.11 & & 0.06 & $0.64^{\mathrm{b}}$ & -0.26 & 0.31 \\
\hline Chitotriosidase & 0.33 & 0.29 & 0.06 & 0.21 & & 0.21 & 0.33 & 0.25 \\
\hline YKL-40 & 0.12 & 0.10 & 0.36 & $0.53^{\mathrm{b}}$ & 0.22 & & -0.07 & 0.25 \\
\hline MMSE & -0.08 & 0.09 & -0.13 & 0.33 & 0.09 & -0.18 & & $-0.60^{\mathrm{b}}$ \\
\hline Age & -0.39 & -0.24 & 0.09 & 0.24 & 0.15 & 0.27 & 0.18 & \\
\hline
\end{tabular}

${ }^{\mathrm{a}} \mathrm{p}<0.05 ;{ }^{\mathrm{b}} \mathrm{p}<0.01 ;{ }^{\mathrm{c}} \mathrm{p}<0.0001$.

\section{Results}

\section{Biomarker Levels}

Patients with AD had significantly higher CSF levels of chitotriosidase (133\% increase) and YKL-40 (77\% increase) compared with controls (table 1, fig. 1). Levels of MCP-1 were not significantly different between groups. The significant group differences for chitotriosidase and YKL-40 remained also when outliers were removed from the groups (data not shown).

\section{Correlations}

Correlations between biomarkers, age and MMSE scores are shown in table 2. There were significant correlations between MCP-1 and YKL-40 in both AD patients and controls $(\mathrm{r}=$ $0.53, p<0.01$ and $r=0.64, p<0.01$, respectively). No biomarker, except for T-tau in controls $(\mathrm{r}=0.40, \mathrm{p}<0.05)$, correlated significantly with age. In addition, no biomarker correlated with MMSE score.

ROC Analysis

ROC plots for the biomarkers are shown in figure 2. The AUROC was 0.78 [95\% confidence interval (CI) 0.65-0.91] for chitotriosidase, 0.88 (95\% CI 0.78-0.98) for YKL-40 and 0.61 (95\% CI $0.45-0.77$ ) for MCP-1 for discriminating AD patients from controls.

\section{Discussion}

Today, there are three CSF biomarkers, T-tau, P-tau and A $\beta 42$, which have proven to be strongly associated with AD [4]. New biomarkers are important to improve the diagnosis and prediction as well as follow-up of AD patients. In this study, we evaluated inflammatory CSF biomarkers and found that patients with AD had higher levels of chitotriosidase and YKL-40 compared with controls, while the levels of MCP-1 were similar between the groups.

We confirmed earlier reported differences in CSF chitotriosidase levels between AD patients and controls $[20,21]$. Even though there was an overlap in the biomarker levels between the groups, it was not as prominent as could be seen in one of the previous studies [20]. This is most likely due to the fact that in the present study, patients were included if having a positive CSF AD biomarker profile, which increases the certainty of including patients with $\mathrm{AD}$ pathology in the $\mathrm{AD}$ group and excluding patients with this pathology in the 
Rosén et al.: Increased Levels of Chitotriosidase and YKL-40 in Cerebrospinal Fluid from Patients with Alzheimer's Disease

Fig. 2. ROC curves of the inflammatory biomarkers for the differentiation between $\mathrm{AD}$ patients and controls.

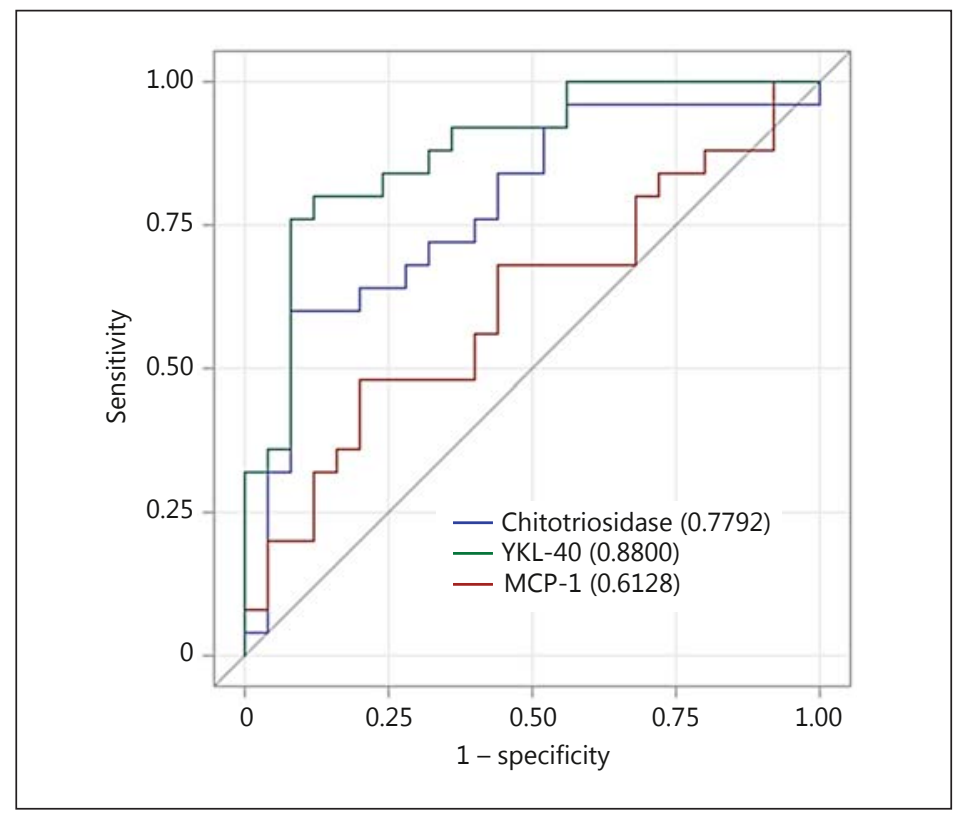

control group. This gives more reliable and biologically relevant results. The approach of biomarker-supported $\mathrm{AD}$ diagnostics is also in line with recently proposed revised criteria for $\mathrm{AD}$ [28].

Similar reasoning applies to studies of YKL-40. Two previous studies report elevated CSF levels of YKL-40 in AD patients in early disease stages [24, 36]. In both of these studies, A $\beta 42$ and T-tau were used for selecting patients. Another study found elevated levels in AD patients but not in MCI patients with incipient AD [25]. However, upon stratification according to an AD-indicative profile of $A \beta 42$ and T-tau, higher levels of YKL- 40 were found in MCI patients who developed $\mathrm{AD}$, compared with stable MCI patients with a normal profile. We corroborate these findings by presenting elevated YKL-40 levels in AD patients. In another study in which biomarker criteria were not applied in the selection of patients, no differences in YKL-40 levels were found between AD patients and controls [20]. Here, YKL-40 achieved an acceptable AUROC of 0.88.

The findings of unaltered MCP-1 levels in AD patients compared with controls are in line with some earlier findings [20], while other studies have found increased levels in AD patients $[26,27]$. Further studies are needed to clarify these discrepancies. A potential confounding factor may be the age of the participants. One study found that AD patients had increased levels of MCP-1 compared with controls, but that the levels correlated with age, and the subjects in the AD group were older than the controls [37]. Moreover, when comparing different methods for MCP-1, suboptimal correlations have been seen [20]. This could either be an indication that the methods detect different fragments of the protein or that there is a need for harmonization of MCP-1 methods. Thus, the divergent results across studies may depend on assay selection.

No inflammatory biomarker correlated with MMSE. The AD patients were older than the controls. However, this probably had no major effect on the results, since no inflammatory biomarker correlated with age. There were no correlations between inflammatory and core AD biomarkers, which indicates that they can provide independent information.

One shortcoming of the study was that only patients with AD were included in the disease group. Hence, we cannot determine the ability of these biomarkers to discriminate AD from other neurodegenerative diseases. 
Rosén et al.: Increased Levels of Chitotriosidase and YKL-40 in Cerebrospinal Fluid from Patients with Alzheimer's Disease

\section{Conclusion}

Patients with AD had higher CSF levels of the inflammatory biomarkers chitotriosidase and YKL-40 compared with controls, while the levels of MCP-1 were similar between the groups. These findings indicate that chitotriosidase and YKL-40 may be used for evaluating inflammatory activity in AD patients.

\section{Acknowledgements}

This is an EU Joint Programme - Neurodegenerative Disease Research (JPND) project (www.jpnd.eu<http://www.jpnd.eu/>). The project is supported through the ISCIII (PI11/03023 to J.L.M.) under the aegis of the JPND. We also gratefully acknowledge the support of the Swedish Research Council, the Alzheimer's Association, the Knut and Alice Wallenberg Foundation and the Leonard Wolfson Experimental Neurology Centre. We thank Dzemila Secic, Monica Christiansson, Åsa Källén and Sara Hullberg for their excellent technical assistance.

\section{References}

1 Blennow K, de Leon MJ, Zetterberg H: Alzheimer's disease. Lancet 2006;368:387-403.

-2 Braak H, Braak E: Diagnostic criteria for neuropathologic assessment of Alzheimer's disease. Neurobiol Aging 1997;18:S85-S88.

-3 Mattsson N, Zetterberg H, Hansson O, Andreasen N, Parnetti L, Jonsson M, Herukka SK, van der Flier WM, Blankenstein MA, Ewers M, Rich K, Kaiser E, Verbeek M, Tsolaki M, Mulugeta E, Rosen E, Aarsland D, Visser PJ, Schroder J, Marcusson J, de Leon M, Hampel H, Scheltens P, Pirttila T, Wallin A, Jonhagen ME, Minthon L, Winblad B, Blennow K: CSF biomarkers and incipient Alzheimer disease in patients with mild cognitive impairment. JAMA 2009;302:385-393.

4 Blennow K, Hampel H, Weiner M, Zetterberg H: Cerebrospinal fluid and plasma biomarkers in Alzheimer disease. Nat Rev Neurol 2010;6:131-144.

5 Rosen C, Hansson 0, Blennow K, Zetterberg H: Fluid biomarkers in Alzheimer's disease - current concepts. Mol Neurodegener 2013;8:20.

6 McKhann GM, Knopman DS, Chertkow H, Hyman BT, Jack CR Jr, Kawas CH, Klunk WE, Koroshetz WJ, Manly JJ, Mayeux R, Mohs RC, Morris JC, Rossor MN, Scheltens P, Carrillo MC, Thies B, Weintraub S, Phelps CH: The diagnosis of dementia due to Alzheimer's disease: recommendations from the National Institute on AgingAlzheimer's Association workgroups on diagnostic guidelines for Alzheimer's disease. Alzheimers Dement 2011;7:263-269.

7 Heneka MT: Inflammation in Alzheimer's disease. Clin Neurosci Res 2006;6:247-260.

-8 Breitner JC, Welsh KA, Helms MJ, Gaskell PC, Gau BA, Roses AD, Pericak-Vance MA, Saunders AM: Delayed onset of Alzheimer's disease with nonsteroidal anti-inflammatory and histamine H2 blocking drugs. Neurobiol Aging 1995;16:523-530.

-9 Breitner JC, Gau BA, Welsh KA, Plassman BL, McDonald WM, Helms MJ, Anthony JC: Inverse association of antiinflammatory treatments and Alzheimer's disease: initial results of a co-twin control study. Neurology 1994; 44:227-232.

10 Wisniewski HM, Wegiel J, Wang KC, Lach B: Ultrastructural studies of the cells forming amyloid in the cortical vessel wall in Alzheimer's disease. Acta Neuropathol 1992;84:117-127.

-11 Wisniewski HM, Wegiel J: Spatial relationships between astrocytes and classical plaque components. Neurobiol Aging 1991;12:593-600.

12 Lee CY, Landreth GE: The role of microglia in amyloid clearance from the AD brain. J Neural Transm 2010;117: 949-960.

13 Perlmutter LS, Barron E, Chui HC: Morphologic association between microglia and senile plaque amyloid in Alzheimer's disease. Neurosci Lett 1990;119:32-36.

14 Frackowiak J, Wisniewski HM, Wegiel J, Merz GS, Iqbal K, Wang KC: Ultrastructure of the microglia that phagocytose amyloid and the microglia that produce beta-amyloid fibrils. Acta Neuropathol 1992;84:225-233.

15 Neniskyte U, Neher JJ, Brown GC: Neuronal death induced by nanomolar amyloid beta is mediated by primary phagocytosis of neurons by microglia. J Biol Chem 2011;286:39904-39913.

16 von Bernhardi R, Eugenin J: Microglial reactivity to beta-amyloid is modulated by astrocytes and proinflammatory factors. Brain Res 2004;1025:186-193. 
17 Guerreiro R, Wojtas A, Bras J, Carrasquillo M, Rogaeva E, Majounie E, Cruchaga C, Sassi C, Kauwe JS, Younkin S, Hazrati L, Collinge J, Pocock J, Lashley T, Williams J, Lambert JC, Amouyel P, Goate A, Rademakers R, Morgan K, Powell J, St George-Hyslop P, Singleton A, Hardy J: TREM2 variants in Alzheimer's disease. N Engl J Med 2013;368:117-127.

18 Jonsson T, Stefansson H, Steinberg S, Jonsdottir I, Jonsson PV, Snaedal J, Bjornsson S, Huttenlocher J, Levey AI, Lah JJ, Rujescu D, Hampel H, Giegling I, Andreassen OA, Engedal K, Ulstein I, Djurovic S, Ibrahim-Verbaas C, Hofman A, Ikram MA, van Duijn CM, Thorsteinsdottir U, Kong A, Stefansson K: Variant of TREM2 associated with the risk of Alzheimer's disease. N Engl J Med 2013;368:107-116.

19 Hollak CE, van Weely S, van Oers MH, Aerts JM: Marked elevation of plasma chitotriosidase activity. A novel hallmark of Gaucher disease. J Clin Invest 1994;93:1288-1292.

20 Mattsson N, Tabatabaei S, Johansson P, Hansson O, Andreasson U, Mansson JE, Johansson JO, Olsson B, Wallin A, Svensson J, Blennow K, Zetterberg H: Cerebrospinal fluid microglial markers in Alzheimer's disease: elevated chitotriosidase activity but lack of diagnostic utility. Neuromolecular Med 2011;13:151-159.

-21 Watabe-Rudolph M, Song Z, Lausser L, Schnack C, Begus-Nahrmann Y, Scheithauer MO, Rettinger G, Otto M, Tumani H, Thal DR, Attems J, Jellinger KA, Kestler HA, von Arnim CA, Rudolph KL: Chitinase enzyme activity in CSF is a powerful biomarker of Alzheimer disease. Neurology 2012;78:569-577.

-22 Hakala BE, White C, Recklies AD: Human cartilage gp-39, a major secretory product of articular chondrocytes and synovial cells, is a mammalian member of a chitinase protein family. J Biol Chem 1993;268:25803-25810.

-23 Bonneh-Barkay D, Wang G, Starkey A, Hamilton RL, Wiley CA: In vivo CHI3L1 (YKL-40) expression in astrocytes in acute and chronic neurological diseases. J Neuroinflammation 2010;7:34.

24 Craig-Schapiro R, Perrin RJ, Roe CM, Xiong C, Carter D, Cairns NJ, Mintun MA, Peskind ER, Li G, Galasko DR, Clark CM, Quinn JF, D’Angelo G, Malone JP, Townsend RR, Morris JC, Fagan AM, Holtzman DM: YKL-40: a novel prognostic fluid biomarker for preclinical Alzheimer's disease. Biol Psychiatry 2010;68:903-912.

25 Olsson B, Hertze J, Lautner R, Zetterberg H, Nagga K, Hoglund K, Basun H, Annas P, Lannfelt L, Andreasen N, Minthon L, Blennow K, Hansson O: Microglial markers are elevated in the prodromal phase of Alzheimer's disease and vascular dementia. J Alzheimers Dis 2013;33:45-53.

-26 Galimberti D, Schoonenboom N, Scheltens P, Fenoglio C, Bouwman F, Venturelli E, Guidi I, Blankenstein MA Bresolin N, Scarpini E: Intrathecal chemokine synthesis in mild cognitive impairment and Alzheimer disease. Arch Neurol 2006;63:538-543.

-27 Correa JD, Starling D, Teixeira AL, Caramelli P, Silva TA: Chemokines in CSF of Alzheimer's disease patients. Arq Neuropsiquiatr 2011;69:455-459.

28 Dubois B, Feldman HH, Jacova C, Cummings JL, Dekosky ST, Barberger-Gateau P, Delacourte A, Frisoni G, Fox NC, Galasko D, Gauthier S, Hampel H, Jicha GA, Meguro K, O’Brien J, Pasquier F, Robert P, Rossor M, Salloway S, Sarazin M, de Souza LC, Stern Y, Visser PJ, Scheltens P: Revising the definition of Alzheimer's disease: a new lexicon. Lancet Neurol 2010;9:1118-1127.

29 Diagnostic and Statistical Manual of Mental Disorders: DSM-III-R, ed 3. Washington, American Psychiatric Association, 1987.

30 McKhann G, Drachman D, Folstein M, Katzman R, Price D, Stadlan EM: Clinical diagnosis of Alzheimer's disease: report of the NINCDS-ASRSA Work Group under the auspices of Department of Health and Human Services Task Force on Alzheimer's Disease. Neurology 1984;34:939-944.

-31 Malmestrom C, Axelsson M, Lycke J, Zetterberg H, Blennow K, Olsson B: CSF levels of YKL-40 are increased in MS and replaces with immunosuppressive treatment. J Neuroimmunol 2014;269:87-89.

-32 Rosen C, Rosen H, Andreasson U, Bremell D, Bremler R, Hagberg L, Rosengren L, Blennow K, Zetterberg H: Cerebrospinal fluid biomarkers in cardiac arrest survivors. Resuscitation 2014;85:227-232.

-33 Vanderstichele H, Van Kerschaver E, Hesse C, Davidsson P, Buyse MA, Andreasen N, Minthon L, Wallin A, Blennow K, Vanmechelen E: Standardization of measurement of beta-amyloid(1-42) in cerebrospinal fluid and plasma. Amyloid 2000;7:245-258.

-34 Blennow K, Wallin A, Agren H, Spenger C, Siegfried J, Vanmechelen E: Tau protein in cerebrospinal fluid: a biochemical marker for axonal degeneration in Alzheimer disease? Mol Chem Neuropathol 1995;26:231-245.

-35 Vanmechelen E, Vanderstichele H, Davidsson P, Van Kerschaver E, Van Der Perre B, Sjogren M, Andreasen N, Blennow K: Quantification of tau phosphorylated at threonine 181 in human cerebrospinal fluid: a sandwich ELISA with a synthetic phosphopeptide for standardization. Neurosci Lett 2000;285:49-52.

-36 Perrin RJ, Craig-Schapiro R, Malone JP, Shah AR, Gilmore P, Davis AE, Roe CM, Peskind ER, Li G, Galasko DR, Clark CM, Quinn JF, Kaye JA, Morris JC, Holtzman DM, Townsend RR, Fagan AM: Identification and validation of novel cerebrospinal fluid biomarkers for staging early Alzheimer's disease. PloS One 2011;6:e16032.

-37 Blasko I, Lederer W, Oberbauer H, Walch T, Kemmler G, Hinterhuber H, Marksteiner J, Humpel C: Measurement of thirteen biological markers in CSF of patients with Alzheimer's disease and other dementias. Dement Geriatr Cogn Disord 2006;21:9-15. 